\title{
Microstructure of Z-phase strengthened martensitic steels: meeting the $650^{\circ} \mathrm{C}$ challenge
}

\author{
$\underline{\text { Fang Liu }}^{1, a^{*}}$, Masoud Rashidi ${ }^{1, b}$, John Hald ${ }^{2, \mathrm{c}}$, Lutz Reißig ${ }^{2, \mathrm{~d}}$ \\ and Hans-Olof Andrén ${ }^{1, \mathrm{e}}$

\begin{abstract}
${ }^{1}$ Department of Physics, Chalmers University of Technology, SE-412 96 Gothenburg, Sweden
\end{abstract} \\ ${ }^{2}$ Department of Mechanical Engineering, Technical University of Denmark, DK 2800 Kgs. Lyngby, \\ Denmark \\ ${ }^{3}$ Fraunhofer Institute for Mechanics of Materials IWM Freiburg, 79108 Freiburg, Germany \\ afang.liu@chalmers.se, ${ }^{b}$ masoud.rashidi@chalmers.se, ${ }^{c}$ jhald@mek.dtu.dk, \\ dutz.reissig@iwm.fraunhofer.de, eandren@chalmers.se
}

Keywords: Z-phase strengthening, precipitation, scanning electron microscopy, transmission electron microscopy, atom probe tomography

\begin{abstract}
We studied three series of Z-phase strengthened steels using scanning electron microscopy, transmission electron microscopy, and atom probe tomography to reveal the detailed microstructure of these steels. In particular, the phase transformation from $\mathrm{M}(\mathrm{C}, \mathrm{N})$ to Z-phase $(\mathrm{CrMN})$ was studied. Carbon content in the steels is the governing factor in this transformation. The impact toughness of some test alloys was rather low. This is attributed to the formation of a continuous $\mathrm{W}$-rich film along prior austenite grain boundaries. $\mathrm{Cu}$ and $\mathrm{C}$ addition to the test alloys changed Laves phase morphology to discrete precipitates and improved toughness dramatically. BN particles were found in some steels. Formation of $\mathrm{BN}$ is directly linked to the $\mathrm{B}$ concentration in the steels.
\end{abstract}

\section{Introduction}

Martensitic $9-12 \%$ chromium steels are used for components in steam power plants, such as pipes, rotors and turbine housings. The thermal efficiency of these plants is limited by the maximum allowed steam temperature and pressure, which in turn are determined by the long-term creep and corrosion resistance of economically viable materials. Previous attempts to increase the service temperature of $9-12 \% \mathrm{Cr}$ steels from $600^{\circ} \mathrm{C}$ to $650^{\circ} \mathrm{C}$ have failed. In these trials, in order to achieve sufficient corrosion resistance at $650^{\circ} \mathrm{C}$, up to $11-12 \%$ chromium (instead of $9 \%$ ) was added. However, a dramatic drop in creep strength occurred after a few thousand hours at $650^{\circ} \mathrm{C}$ [1]. The reason for the catastrophic loss of creep resistance lies in a phase transformation of a family of precipitates: the fine dispersion of $\mathrm{VN}$ precipitates is replaced by coarse precipitates of Zphase $\mathrm{Cr}(\mathrm{Nb}, \mathrm{V}) \mathrm{N}$.

In 2009 following a suggestion by Hald and Danielsen, the development of a new family of steels was initiated [2]. The aim of the alloy development was to introduce for strengthening a fine and slowly coarsening dispersion of Z-phase instead of VN. A high (12\%) Cr content is a prerequisite for quick Z-phase precipitation. Thus, both good corrosion and creep resistance are achieved. This novel alloy design concept was proved feasible [3].

Recently, within the frame of the EU FP7 project, "Z-ultra", a team of European researchers from both academia and industry gathered together, dedicated to optimizing the alloy design and further developing this new generation of $12 \% \mathrm{Cr}$ steels. Three series of test alloys have been designed, produced and characterized. All of them contained $11-12 \% \mathrm{Cr}$, and $\mathrm{Ta}$ or $\mathrm{Nb}$ to form $\mathrm{Z}$ phase of type $\mathrm{CrTaN}$ or $\mathrm{CrNbN}$. The creep resistance of the test alloys was between the levels of the 
standard steels P91 and P92. Within the work package "Nanoscale Experiment", we used scanning electron microscopy (SEM), transmission electron microscopy (TEM), and atom probe tomography (APT) to reveal the detailed microstructure of these steels. The aim is to establish the correlation between the steels' chemical composition, microstructure, and mechanical properties. Together with other colleagues, who work with modeling, welding, alloy production, and power plant applications, we would like to use this new generation of alloys to push the application temperature of future steam power plants to $650^{\circ} \mathrm{C}$ based on martensitic/ferritic steels.

Within the scope of this paper, we would like to give a rather brief overview on the microstructure of these novel steels. More detailed results have been [3-6] or will be published by the authors. Parallel work done within other work packages of this project can also be found in this issue of the publication.

\section{Materials and experimental}

Materials. Three series of Z-phase strengthened test steels, (referred to as S1, S2 and S3), were produced by Saarschmiede $\mathrm{GmbH}$. The chemical compositions for the eight test alloys are provided in Table 1. Heat treatment conditions for the steels are slightly different:

- test alloy $\mathrm{S} 1$ was austenitized at $1150^{\circ} \mathrm{C}$ for 1 hour, and then underwent two-stage tempering - first stage at $650{ }^{\circ} \mathrm{C}$ for 6 hours, and second stage at $740{ }^{\circ} \mathrm{C}$ for 6 hours.

- all S2 and S3 series alloys were austenitized at $1100^{\circ} \mathrm{C}$ for 1 hour, and then underwent two-stage tempering - first stage at $650^{\circ} \mathrm{C}$ for 4 hours, and second stage at $750^{\circ} \mathrm{C}$ for 2 hours.

Table 1. Chemical composition of the test Z-phase strengthened steels in weight percent (Fe in balance).

\begin{tabular}{|c|c|c|c|c|c|c|c|c|c|c|c|c|}
\hline Steel & $\mathbf{N i}$ & Co & $\mathrm{Cr}$ & $\mathbf{W}$ & Ta & C & B & $\mathbf{N}$ & Si & Mn & $\mathrm{Cu}$ & Other \\
\hline S1 & 0.19 & 3.5 & 12.1 & 2.47 & 0.36 & 0.06 & 0.0063 & 0.049 & 0.31 & 0.21 & 1.95 & - \\
\hline$S 2-1$ & 0.18 & 2.7 & 11.2 & 2.0 & 0.35 & 0.028 & 0.0042 & 0.045 & 0.34 & 0.12 & 2.00 & - \\
\hline S2-2 & 0.17 & 3.1 & 11.2 & 2.1 & 0.19 & 0.03 & 0.0054 & 0.042 & 0.32 & 0.13 & 2.10 & $\begin{array}{c}\mathrm{Nb} \\
0.16\end{array}$ \\
\hline S2-3 & 0.20 & 3.1 & 11.1 & 1.8 & 0.43 & 0.05 & 0.0042 & 0.036 & 0.23 & 0.12 & - & $\begin{array}{c}\text { Mo } \\
0.50\end{array}$ \\
\hline S3-1 & 0.11 & 3.93 & 11.45 & 2.02 & 0.38 & 0.013 & 0.0026 & 0.046 & 0.29 & 0.08 & 2.01 & - \\
\hline S3-2 & 0.11 & 5.65 & 11.46 & 2.47 & 0.40 & 0.012 & 0.0026 & 0.042 & 0.28 & 0.09 & 1.02 & - \\
\hline S3-3 & 0.08 & 5.11 & 11.33 & 2.32 & 0.41 & 0.011 & 0.0042 & 0.043 & 0.30 & 0.10 & 2.01 & - \\
\hline S3-4 & 0.11 & 5.60 & 11.30 & 2.68 & 0.43 & 0.009 & 0.0025 & 0.041 & 0.30 & 0.93 & 1.54 & _ \\
\hline
\end{tabular}

Scanning electron microscopy. A Leo Ultra 55 Field Emission Gun SEM (FEG-SEM) was used. It is equipped with an Oxford Inca energy dispersive X-ray spectroscopy (EDS) system. The 
operational voltages were between 5 and $20 \mathrm{kV}$. SEM specimens were prepared by the standard grinding and polishing processes.

Transmission electron microscopy. An FEI Tecnai TEM equipped with a $\mathrm{LaB}_{6}$ gun operated at $200 \mathrm{kV}$ and a spherical-aberration-corrected FEI Titan 80-300 TEM were for a detailed characterization of the microstructure of steels. Three-millimeter disk-shaped TEM specimens, i.e. with electron transparent regions, were prepared by electropolishing using a TenuPol 5 dual-jet electropolishing unit.

Atom Probe Tomography. APT is the only tool that can yield chemical composition of individual atoms with sub-nanometer spatial resolution. The typical analysis volume is about $80 \times 80 \times 100$ $\mathrm{nm}^{3}$ [7]. An Imago LEAP 3000X HR local electrode APT was used. During analysis the specimen was held at a temperature of 55-56 K. The instrument was operated in the pulsed laser mode with a laser pulse energy of $0.3 \mathrm{~nJ}$ [8]. The data collected by the instrument was further analyzed using the IVAS 3.4.6 software. APT specimens with a final tip radius $<50 \mathrm{~nm}$ were prepared using two-stage electropolishing procedure [9].

\section{Results and Discussion}

General microstructure. All the test steels exhibit a lath martensite structure, and a typical example is shown in Fig. 1 (a), which is a SEM backscattered electron micrograph obtained from the test steel S1 after 5500 hours of aging. There are also a large number of precipitates (particles with bright and grey contrast) visible in this micrograph. Besides some large (on the micrometer level) inclusions (e.g. $\mathrm{Al}_{2} \mathrm{O}_{3}, \mathrm{MnS}$ ) and primary precipitates (e.g. tantalum carbide, tantalum oxide, and in some alloys BN), there are mainly four families of small (on the nanometer level) secondary precipitates in the alloys:

- Ta-containing precipitates, $\mathrm{MX}(\mathrm{Ta}(\mathrm{C}, \mathrm{N}))$ or Z-phase $(\mathrm{CrTaN})$ or some intermediate form between these two phases (more detail in next subsection);

- Laves phase $\left(\mathrm{Fe}_{2} \mathrm{~W}\right)$;

- Carbides $\left(\mathrm{M}_{23} \mathrm{C}_{6}\right)$; and

- Cu particles.

The SEM backscattered electron micrograph with a higher magnification (Fig. 1 (b)) shows more clearly these relatively small precipitates. Most of the precipitates are located along lath or prior austenite grain boundaries. The evolution of the size, volume fraction, and chemical composition of different families of precipitates vary to a rather large extent in the test steels, despite that the chemical compositions of the steels only vary to a very small extent.
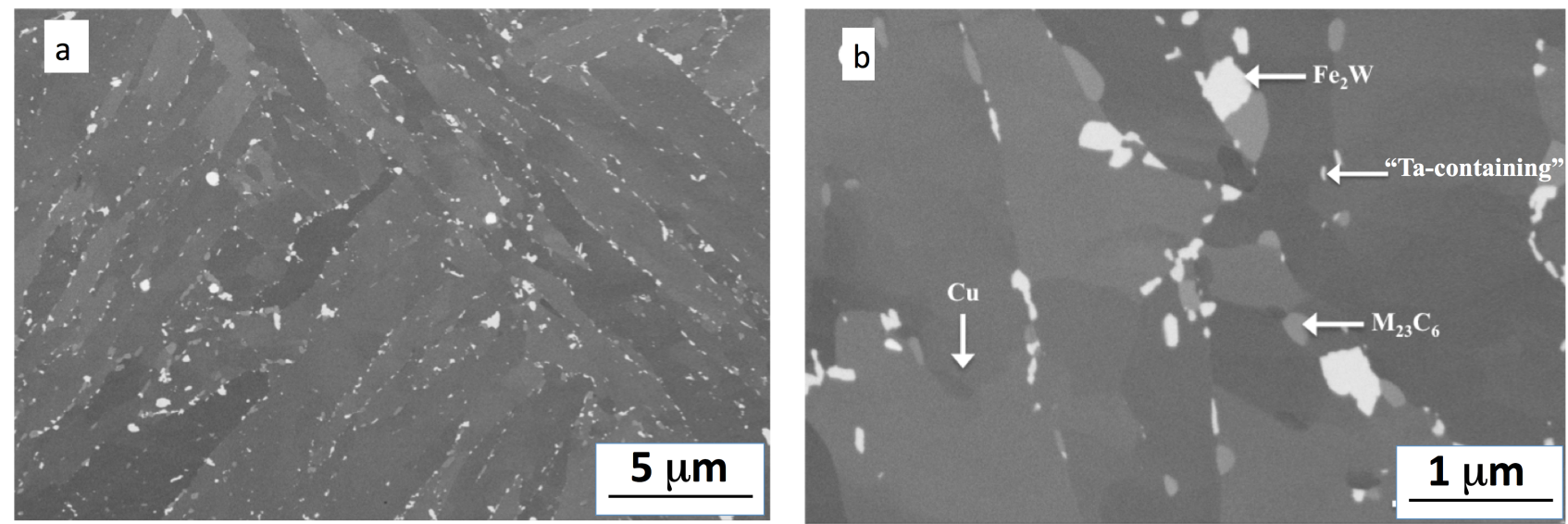

Fig. 1 SEM backscattered electron micrographs of steel S1 after aging for $5500 \mathrm{~h}$, showing a) the martensite lath structure; b) different types of precipitates: Ta-containing, Laves phase $\left(\mathrm{Fe}_{2} \mathrm{~W}\right), \mathrm{M}_{23} \mathrm{C}_{6}$, and $\mathrm{Cu}$. 
Formation of Z-phase. Although TEM imaging can reveal the size and distribution of small precipitates, APT is more powerful in identifying their chemistry, in particular the Ta-containing precipitates. Fig. 2 (a) is a TEM bright field micrograph obtained from S3-1 in the as-tempered condition. It shows a large number of small $(\sim 10 \mathrm{~nm})$ precipitates in the steel. However, just based on TEM imaging we cannot tell whether these precipitates are MX or Z-phase. On the other hand, chemical composition of the precipitates provides a reliable indication of the phase. To obtain an accurate chemical composition is extremely difficult for such small precipitates by using TEM related microanalysis methods, such as EDX, because for the small precipitates there is a strong influence from the steel matrix, and the EDX signals from the precipitate itself are thus very low. Despite the so-called "local magnification effect", APT is an unparalleled tool for analyzing chemical composition of small features. Fig. 2 (b) is an APT reconstruction of a small volume of S3-1 in the as-tempered condition. For visual clarity only a small portion of $\mathrm{Cr}$ atoms (small dots) are shown in the figure to outline the reconstructed volume of the matrix. Iso-concentration surfaces enable visualization of phases with different chemical concentrations. The purple surfaces illustrate Ta-containing precipitates. All the atoms inside the iso-concentration surfaces can be extracted and analyzed, thus giving accurate chemical compositions of individual precipitates.

One of the most essential requirements for the success of Z-phase strengthened steels is to form thermodynamically stable Z-phase precipitates within relatively short period of time during heat treatment or service. In conventional $9-12 \% \mathrm{Cr}$ steels at $600^{\circ} \mathrm{C}$, Z-phase precipitates are difficult to form; normally several ten thousand hours are needed [10] to form a very low number of Z-phase precipitates. It was believed that the reason for the long transformation time lies in the slow nucleation rate of Z-phase precipitates. It was recently found that the formation of Z-phase does not actually follow the classic nucleation theory for phase transformation, i.e. forming nuclei, growing and coarsening. High resolution scanning TEM showed elegantly that layers of $\mathrm{Cr}$ atoms squeeze into the cubic lattice plane of MX precipitates, and thus the metastable MX gradually transforms into Z-phase [11]. This explains why even diffraction in TEM cannot accurately identify the phases.
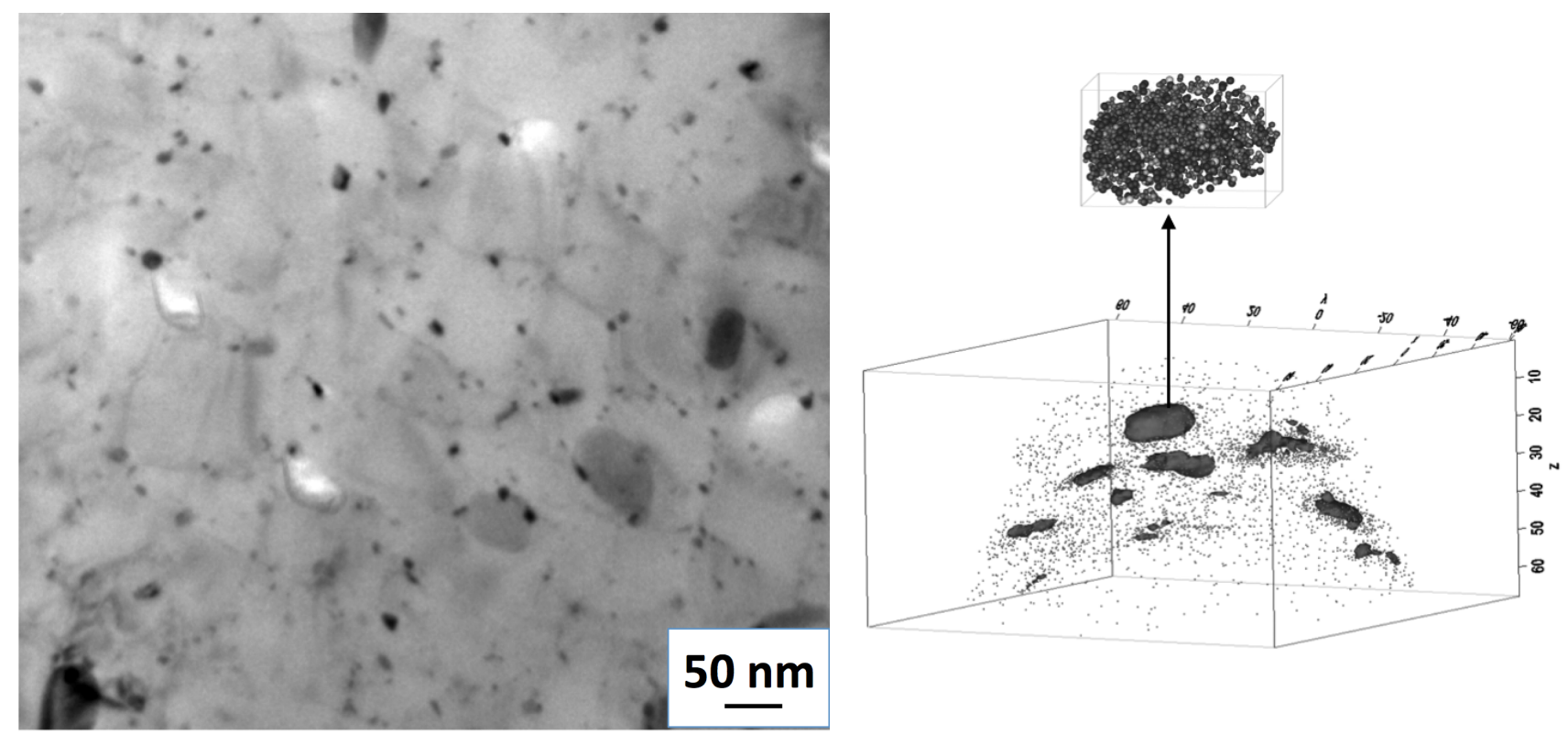

Fig. 2 TEM bright field micrograph of S3-1 in the as-tempered condition, showing many small precipitates (dark contrast) with a size around $10 \mathrm{~nm}$; b) An APT reconstruction showing small Ta-rich precipitates. Big box size $125 \times 125 \times 68 \mathrm{~nm}^{3}$. The extracted box shows atoms inside one of the precipitates, box size $15 \times 15 \times 10 \mathrm{~nm}^{3}$.

The ratio between $\mathrm{Cr}$ and Ta was used as an indication for the level of transformation from MX to Z-phase. The $\mathrm{Cr}$ concentration is very low in MX precipitates, while rather high in Z-phase. Instead of the nominal chemical composition of $\mathrm{CrTaN}$, where the $\mathrm{Cr}$ and $\mathrm{Ta}$ ratio equals one, in a rather similar Z-phase strengthened steel the ratio was found to be much higher: $\mathrm{Cr}: \mathrm{Ta} \approx 1.2: 0.8$ [3]. 
APT analysis results on the small precipitates showed a wide range of $\mathrm{Cr}$ to $\mathrm{Ta}$ ratio, indicating that the transformation to Z-phase is a continuous process. In addition, this ratio is very sensitive to the $\mathrm{C}$ concentration in the steels. Fine Z-phase precipitates had formed after $24 \mathrm{~h}$ aging at $650^{\circ} \mathrm{C}$ in steels with very low carbon content $(0.005 \%)$ [3]. In steels that contained more carbon, the transformation from $\mathrm{Ta}(\mathrm{C}, \mathrm{N})$ to Z-phase was more sluggish, such as $\mathrm{S} 1$ and S2-3. In addition, in steels that contained a mixture of $\mathrm{Ta}$ and $\mathrm{Nb}(\mathrm{S} 2-2),(\mathrm{Ta}, \mathrm{Nb})(\mathrm{C}, \mathrm{N})$ precipitates of varying composition were formed, and it seems that the precipitates that contained more $\mathrm{Nb}$ transformed into Z-phase quicker.

Formation of Laves phase. In the new alloys, Laves phase precipitates usually form within a rather short period of time at $650^{\circ} \mathrm{C}$. Small Laves precipitates (less than $200 \mathrm{~nm}$ ) were formed just after tempering. On the other hand, at $600^{\circ} \mathrm{C}$ it usually takes several hundred hours to form Laves phase [12]. The impact toughness of some test alloys was very low, S3-2, S3-3 and S3-4. Particularly, in these steels continuous $\mathrm{W}$-rich films were often formed along some of the prior austenite grain boundaries (PAGBs). A typical example is shown in Fig 3, which is a high angle annular dark field (HAADF) TEM micrograph obtained from steel S3-2 in the as-tempered condition. The brittleness is attributed to the formation of continuous W-rich films. It was reported that $\mathrm{Cu}$ addition into similar alloys can change Laves morphology to discrete precipitates and improves toughness dramatically [5]. The major effect of $\mathrm{Cu}$ seems to be the formation of $\mathrm{Cu}$ precipitates that act as nucleation sites for Laves precipitates. In steels with a relatively high carbon content (S1) the formation of $\mathrm{M}_{23} \mathrm{C}_{6}$ at PAGBs also prevents the formation of W-rich films.

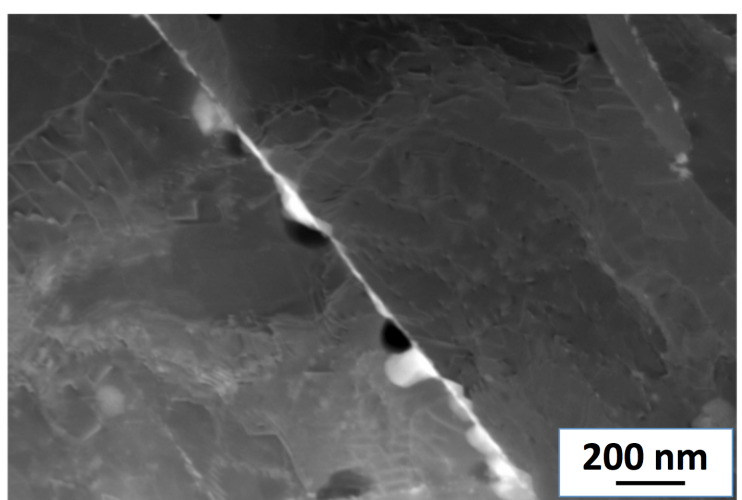

Fig. 3 STEM/HAADF micrograph showing a PAGB decorated with several Laves phase precipitates and a $W$-rich film (the line with the bright contrast). The sample is electropolished $\mathrm{S3-2}$ in the as-tempered condition.

Formation of BN. Among all the steels, we found BN particles in the steels S1, S2-1, S2-2, S2-3, and S3-3. Due to their low atomic numbers, the BN particles exhibit a dark contrast in SEM backscattered electron micrographs (Fig. 4). Their sizes are large (often $>1 \mu \mathrm{m}$ ). The B concentration in these alloys is high ( $>40 \mathrm{ppm})$, and this explains the formation of BN. According to Abe [13], when the $\mathrm{N}$ concentration is high $(\sim 0.04 \mathrm{wt} \%)$ as in all the test steels, the $\mathrm{B}$ concentration in all steels ( $>20 \mathrm{ppm}$ ) is far beyond the ratio for forming BN. In fact, formation of coarse BN is expected in all alloys. Work is now under progress to modify Abe's model to fit Zphase strengthened steels.

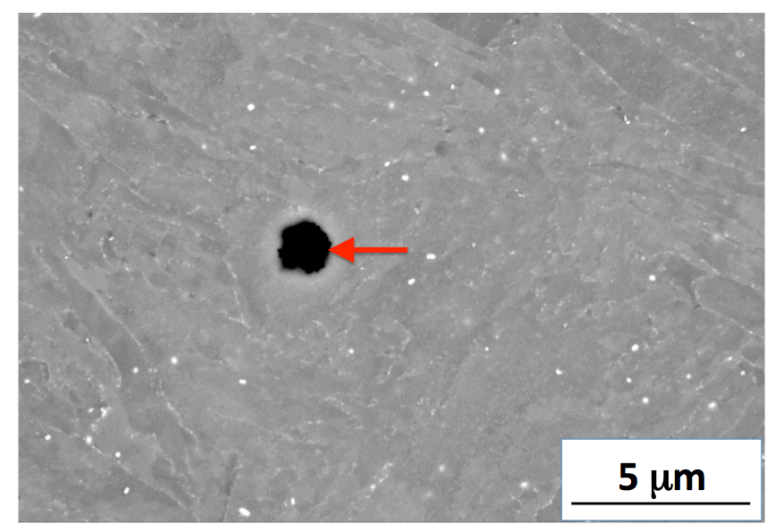

Fig. 4 SEM backscattered electron micrographs of steel S3-3 in as-tempered condition, showing a BN particle (the dark contrast). 


\section{Summary}

All the new Z-phase strengthened $12 \% \mathrm{Cr}$ steels exhibit a martensite lath structure. The rate of the phase transformation from MX to Z-phase depends, among other things, on the $\mathrm{C}$ content in the steel. Formation of Laves phase and W-rich films along PAGBs results in poor impact toughness in some test steels. Addition of $\mathrm{Cu}$ and $\mathrm{C}$ can improve their toughness. BN particles formed in steels with relatively high $\mathrm{B}$ content.

\section{Acknowledgements}

All authors acknowledge the EU FP7 project Z-ultra (contract number: 309916) FL, MR and HOA are grateful for the financial support by the Swedish research program KME (contract numbers: 510 and 710), and the Research Foundation of VGB (contract number: 348 and 397) in Germany. FL is partly funded via LIGHTer, a programme financed within Strategic Innovation Areas, a mutual venture between VINNOVA, the Swedish Energy Agency, and Formas.

\section{References}

[1] T. Uehara, A. Toji, S. Komatsubara, T. Fujita, in: J. Lecomte-Beckers, M. Carton, F. Schubert, P.J. Ennis (Eds.) Materials for advanced power engineering, Forschungszentrum Jülich GmbH, Liege, Belgium, 2002, pp. 1311-1320.

[2] H.K. Danielsen, J. Hald, VGB PowerTech, Influence of Z-phase on long-term creep stability of martensitic 9 to $12 \%$ Cr steels, 5 (2009) 68-73.

[3] F. Liu, M. Rashidi, L. Johansson, J. Hald, H.O. Andren, A new 12\% chromium steel strengthened by Z-phase precipitates, Scripta Materialia, 113 (2016) 93-96.

[4] F. Liu, H.-O. Andrén, Initial study on Z-phase strengthened 9-12\% Cr steels by atom probe tomography, 9th Liège Conference on materials for anvanced power engineering, Liège, Belgium, 2010, pp. Paper 12.

[5] F. Liu, H.-O. Andrén, Effect of $\mathrm{Cu}$ addition on the toughness of new Z-phase strengthened 12\% Cr steels, EPRI 7th International Conference on Advances in Materials Technology for Fossil Power Plants, Hawaii, USA, 2013.

[6] M. Rashidi, F. Liu, H.-O. Andrén, Microstructure characterization of two Z-phase strengthened $12 \%$ Chromium steels, 10th Liège Conference on Materials for Advanced Power Engineering, Liège, Belgium, 2014.

[7] A. Cerezo, P.H. Clifton, M.J. Galtrey, C.J. Humphreys, T.F. Kelly, D.J. Larson, S. LozanoPerez, E.A. Marquis, R.A. Oliver, G. Sha, K. Thompson, M. Zandbergen, R.L. Alvis, Atom probe tomography today, Materials Today, 10 (2007) 36-42.

[8] F. Liu, H.-O. Andrén, Effects of laser pulsing on analysis of steels by atom probe tomography, Ultramicoscopy, 111 (2011) 633-641.

[9] A. Golpayegani, F. Liu, H. Svensson, M. Andersson, H.-O. Andrén, Microstructure of a creep resistant $10 \%$ chromium steel containing $250 \mathrm{ppm}$ boron, Metallurgical and Materials Transactions A 42 (2011) 940-951.

[10] K. Sawada, H. Kushima, K. Kimura, Z-phase Formation during Creep and Aging in 9-12 \% Cr Heat Resistant Steels, ISIJ International, 46 (2006) 769-775.

[11] H.K. Danielsen, J. Hald, M.A.J. Somers, Atomic resolution imaging of precipitate transformation from cubic TaN to tetragonal CrTaN, Scripta Materialia, 66 (2012) 261-264.

[12] F. Abe, Creep rates and strengthening mechanisms in tungsten-strengthened $9 \mathrm{Cr}$ steels, Materials Science \& Engineering A, A319-321 (2001) 770-773.

[13] H. Semba, F. Abe, Creep Deformation Behavior and Microstructure in High Boron Containing 9\% Cr Ferritic Heat-Resistant Steels in: R. Viswanathan, D. Gandy, K. Coleman (Eds.) The 4th international conference on advances in materials technology for possil power plants, ASM international, Hilton Head Island, SC, USA, 2004, pp. 1229. 